\title{
Management of secretory otitis media: a prospective randomised study comparing medical management with early surgical intervention
}

\author{
Rajprakash D. Y. ${ }^{1}$, Sithananda Kumar Venkatesan R. ${ }^{2 *}$, Alisulthan A. R. ${ }^{3}$, \\ Aravindhan.$^{3}$, Mothilal K. B. ${ }^{3}$
}

Department of ENT, ${ }^{1}$ Satya Sai Medical College and Research Institute, Chennai, ${ }^{2}$ Pondicherry Institute of Medical Sciences, Pondicherry, ${ }^{3}$ Coimbatore Medical College, Coimbatore, Tamil Nadu, India

Received: 20 April 2019

Revised: 03 May 2019

Accepted: 06 May 2019

\section{*Correspondence:}

Dr. Sithananda Kumar Venkatesan R.,

E-mail: drkumar123@gmail.com

Copyright: () the author(s), publisher and licensee Medip Academy. This is an open-access article distributed under the terms of the Creative Commons Attribution Non-Commercial License, which permits unrestricted non-commercial use, distribution, and reproduction in any medium, provided the original work is properly cited.

\begin{abstract}
Background: Secretory otitis media is the most common cause of conductive hearing loss in children. Though selflimiting recurrent disease can cause speech and language delay, cognitive impairment and behavioural problems in the long term. This is a prospective study of the epidemiological profile, predisposing factors, clinical profile of secretory otitis media. This study also compares the conservative treatment with early surgical Treatment in Patient with secretory otitis media.

Methods: The study is a prospective randomised study of patients presenting with conductive hearing loss diagnosed by pure tone audiometry. The patients were randomized into two groups of 25 patients each. The medical management arm received antihistamines and decongestants and the surgical arm patient underwent myringotomy with grommet insertion. Patients with adenoid hypertrophy underwent adenoidectomy as an additional procedure. The patients were followed up regularly and where evaluated at the end of 12 months for symptomatic improvement and hearing improvement by Pure Tone Audiogram and impedance audiogram.

Results: The most common age group affected was between 5-15 yrs with hard of hearing and aural fullness being the most common presenting complaint. Eustachian tube dysfunction with adenoid hypertrophy was the most common precipitating factor (68\%) followed by allergy and gastro esophageal reflux disease. Compared to medical treatment which resulted in a successful treatment outcome in $40 \%$ of patients, cases which underwent surgical treatment had successful outcome in $70 \%$ of cases.

Conclusions: Surgical management in the form of adenoidectomy/myringotomy with grommet insertion has better long term outcome in terms of hearing impairment and disease relapse and recurrence.
\end{abstract}

Keywords: Secretory oitis media, Myringotomy with grommet, Adenoidectomy

\section{INTRODUCTION}

Secretory otitis media is the most common cause of hearing impairment in children. It is defined as the persistence of serous or mucoid middle ear effusion for 12 weeks or more. ${ }^{1}$ It is also called as otitis media with effusion, catarrhal otitis media, exudative otitis media, seromucinous otitis media, non-suppurative otitis media.
Secretory otitis media is generally self-limiting, but occurs during a period when poor hearing will impede speech and language development. The effects are mostly short term, but in children in whom the condition recurs throughout childhood, some effects on behaviour and cognition are detectable up to the age of 10 years and beyond. $^{2}$ In adults it can lead on to atelectatic otitis media which can sometimes lead on to cholesteatoma formation. 
This study was performed to clinically evaluate and to find out the effective method of managing this condition.

\section{METHODS}

Study design: Prospective randomised study

Place of study: Department of ENT, Coimbatore Government Medical College.

Study period: December 2008- December 2010.

Sample size: 50.

\section{Inclusion criteria}

Inclusion criteria were patients with complaints of hard of hearing/discomfort or blocking sensation of the ear for more than 3 months; otoscopic evidence of secretory otitis media; an impendance audiometry with type ' $\mathrm{B}$ ' or ' $\mathrm{C}$ ' curve; patients with combination of two or more of these criteria were included in the study.

\section{Exclusion criteria}

Exclusion criteria were patients with acute ear pain, ear discharge; patients deaf since childhood or with family history of hard of hearing; patients with cleft palate, beningn and malignant tumors of nasopharynx.

A detailed history was recorded for all patients. All patients were examined with a pneumatic otoscope and the findings were recorded in 3 formats as 1) normal tympanic membrane, 2) a thin semi-transparent tympanic membrane with air bubble or fluid level, 3) a dull or yellowish/ opaque, retracted/ bulging lustreless tympanic membrane with distorted cone of light. All patients were subjected to pure tone audiometry and graphical recording of their hearing threshold were made and the pure tone average in both ears were recorded. Tympanometry was done in all patients. Both tympanometry and acoustic reflex testing were done. Radiological investigations in the form of X-ray PNS (occipito mental view) were done in suspected cases of chronic sinusitis and assessment were made regarding pharyngeal end of Eustachian tube orifice and adenoids by diagnostic nasal endoscopy. Examination under microscope was done to confirm the otoscopic findings. The predisposing factors for otitis media with effusion if present were noted.

One group of patients (25 no's) were given medical treatment for 6 weeks which included:

- Antibiotics, anti inflamatory drugs, antihistamines, nasal decongestants;

- They were instructed to perform valsalva manoeuvre, 3-5 times a day.

Improvement in medical treatment is considered if:
- Patients have symptomatic relief.

- Otoscopically tympanic membrane become normal.

- Pure tone audiometry showed good improvement in hearing air bone gap shows $<10 \mathrm{~dB}$.

If patients satisfy these criteria, improvement was further confirmed by tympanometry.

Other group of patients (25 no's) were subjected to surgical management which includes:

- Myringotomy and grommet insertion,

- Aden tonsillectomy with myringotomy and grommet insertion (Shephards)

These patients were followed regularly. Success of the procedure was assessed by following means:

- Symptomatic improvement

- Otoscopic evidence of improvement.

- Air bone gap $<10 \mathrm{~dB}$ in postoperative audiogram done after 12 months.

\section{RESULTS}

This study is the prospective analysis of the incidence, predisposing factors, clinical profile and the treatment outcome of medical and surgical management conducted in the Department of ENT, Coimbatore Medical College Hospital, Coimbatore.

The demographic profile shows the most common age group affected was between 5 to 15 years. Of the 50 patients studied $58 \%$ (29 patients) were male and $42 \%$ (21 patients) were female. In the various age groups there was no significant difference between male and female patients.

Table 1: The age and sex distribution of patients in the study.

\begin{tabular}{|lll|}
\hline Age (in years) & Male & Female \\
\hline $\mathbf{1 - 1 0}$ & 10 & 10 \\
\hline $\mathbf{1 1 - 2 0}$ & 9 & 7 \\
\hline $\mathbf{2 1 - 3 0}$ & 4 & 1 \\
\hline $\mathbf{3 1 - 4 0}$ & 3 & 2 \\
\hline $\mathbf{4 1 - 5 0}$ & 1 & 2 \\
\hline $\mathbf{5 1 - 6 0}$ & 1 & 0 \\
\hline
\end{tabular}

The most common symptom was hard of hearing which was seen in $68 \%$ of patients followed by ear fullness (54\%), otalgia (48\%), nasal symptoms (26\%). On pneumatic otoscopic examination, most common sign was impaired tympanic membrane mobility which accounted for $92 \%$ of patients, followed by retracted tympanic membrane (60\%), fluid level (44\%).

Eustachian tube function was assessed by diagnostic nasal endoscopy and pneumatic otoscopy. Adenoid 
hypertrophy was the most common predisposing factor found in $66 \%$ of patient, followed by allergy (12\%), GERD (8\%). Though cleft palate is a risk factor for secretary otitis media, we did not encounter any patient with cleft palate.

Table 2: The symptom profile of patients in the study.

\begin{tabular}{|l|l|}
\hline Symptoms & Number of patients \\
\hline Hard of hearing & 34 \\
\hline Otalgia & 24 \\
\hline Ear fullness & 27 \\
\hline Nasal symptoms & 13 \\
\hline
\end{tabular}

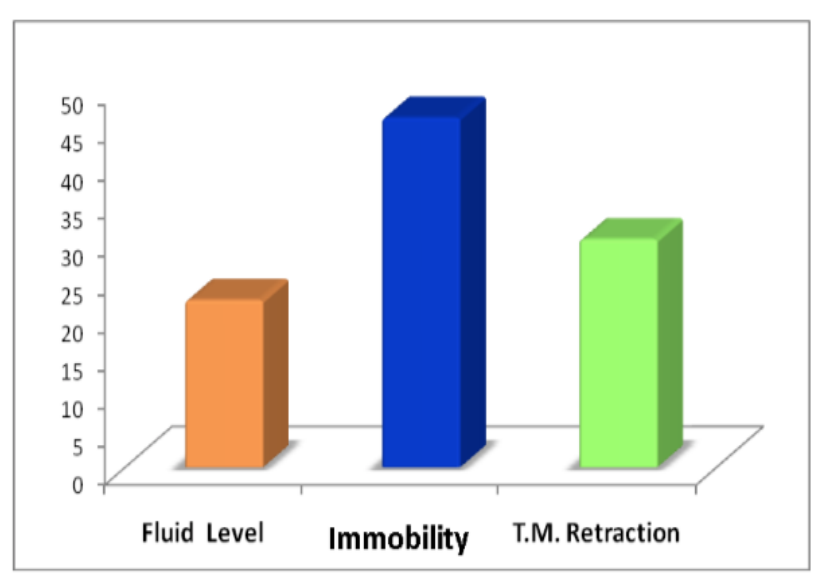

Figure 1: Tympanic membrane findings in the study.

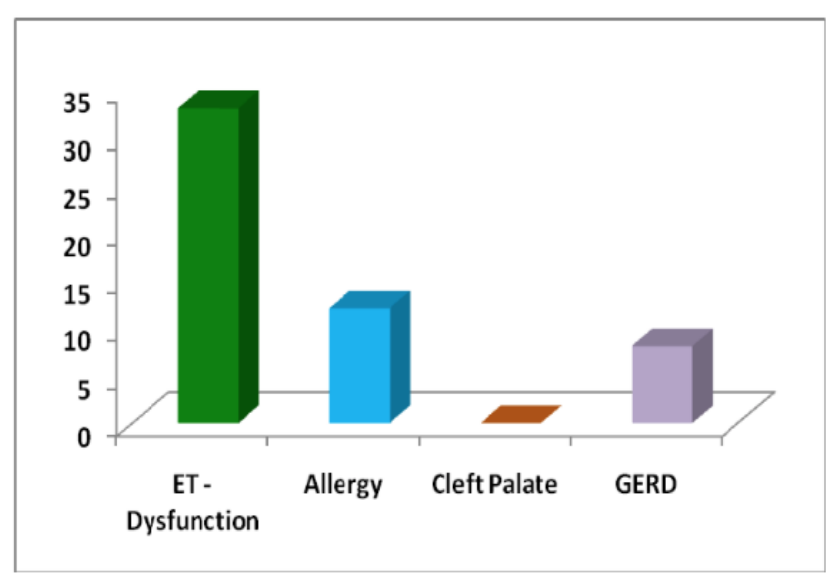

Figure 2: Possible predisposing factors to secretory otitis media in our study.

Majority of the patients had hearing loss in the range of $20-40 \mathrm{db}(69 \%)$. About $77 \%$ of patients had B curve, $23 \%$ patients had ' $\mathrm{C}$ ' curve.

Our patients were randomized into medical treatment arm and surgical treatment arm, and the results were analyzed in terms of symptomatic relief, pure tone audiogram results and pneumatic otoscopy. Out of 25 patients, who were taken up for medical treatment $60 \%$ of patients showed a significant reduction in the air bone gap with air bone gap less than $10 \mathrm{db}$ as compared to the pretreatment values. $52 \%$ of the patients had their tympanic membrane returned to normal appearance. Only $20 \%$ of the patients had symptomatic relief.

Table 3: The degree of hearing loss in the study.

\begin{tabular}{|lll|}
\hline Hearing loss $(\mathbf{d b})$ & \multicolumn{2}{l|}{ Number of patients } \\
\hline $\mathbf{2 0 - 3 0}$ & Right & Left \\
\hline $\mathbf{3 1 - 4 0}$ & 13 & 14 \\
\hline $\mathbf{4 1 - 5 0}$ & 22 & 20 \\
\hline $\mathbf{5 1 - 6 0}$ & 10 & 7 \\
\hline $\mathbf{6 0 - 7 0}$ & 3 & 0 \\
\hline
\end{tabular}

Table 4: The typanometry profile of patients in the study.

\begin{tabular}{|lll|}
\hline \multirow{2}{*}{ Tympanometry } & \multicolumn{2}{l|}{ Number of patients } \\
\hline A & Right & Left \\
\hline Ad & 0 & 0 \\
\hline As & 0 & 0 \\
\hline B & 0 & 0 \\
\hline C & 36 & 41 \\
\hline
\end{tabular}

Considering the patients with 2 of the 3 factors (symptomatic relief, tympanic membrane returned to normal appearance, air bone gap less than $10 \mathrm{db}$ ) as successful outcome of medical treatment, only 40\% (10 patients) had successful outcome. Patients in surgical treatment arm (25 no's) along with patients (15 no's) who were declared as failure of medical management, a total of 40 patients were subjected to surgical management.

Table 5: The treatment results in the medical management group.

\begin{tabular}{|ll|}
\hline Results of medical treatment & Number of patients \\
\hline Symptomatic relief & 7 \\
\hline TM Normal & 13 \\
\hline Air Bone Gap <10 db & 15 \\
\hline
\end{tabular}

Out of the 40 patients who underwent surgical treatment $70 \%$ showed a significant improvement when the above criteria for successful outcome was taken. Of the 15 patients who were taken up for surgical treatment because of failure of medical treatment, 4 patients did not show significant improvement even after surgical treatment.

Table 6: The treatment resuts in surgical management group.

\begin{tabular}{|lc|}
\hline Results of medical treatment & Number of patients \\
\hline Symptomatic relief & 13 \\
\hline TM Normal & 25 \\
\hline Air bone gap $<\mathbf{1 0}$ db & 27 \\
\hline
\end{tabular}




\section{DISCUSSION}

Otitis media is a common disease among infants and young children. ${ }^{1,2}$ Secretory otitis media is the leading cause of hearing loss in children and $20 \%$ of children older than 2 years may develop persistent middle ear effusion that is four weeks or more. ${ }^{1,2}$ Eustachian tube dysfunction is one of the commonly associated problems in OME. Enlarged and infected adenoids the leading cause of Eustachian tube dysfunction in children and young adults. ${ }^{3}$ In our Study, the predominant age group was found to be between 5-15 years. There was no significant difference in the incidence among males $(58 \%)$ and females $(42 \%)$. Zielhius et al reviewed about 23 studies which used tympanometry as one of the diagnostic tool to give age specific prevalence rates and found that the prevalence is bimodal with first peak, at 2 years. $^{2}$

The most common symptom was hard of hearing $(68 \%)$ followed by otalgia (48\%) and nasal symptoms (26\%). Most common sign was impaired tympanic membrane mobility (92\%) followed by retracted tympanic membrane $(60 \%)$ and fluid level/air bubbles (44\%). Among the predisposing factors ET- dysfunction was found in $66 \%$ of patients. About $69 \%$ of the patients had hearing loss in the range of $20-40 \mathrm{db}$, with $77 \%$ of patients had 'B' curve and $23 \%$ of the patients had C' curve. Medical treatment showed a successful outcome in $40 \%$ of patients. The remaining $60 \%$ patients who did not show improvement were subject to surgical treatment. Out of the 40 patients who underwent surgical treatment, $70 \%$ had successful outcome.

Gates and others found that in $45 \%$ of cases treated with antibiotics (erythromycin ethylsuccinate and sulfisoxale), effusion cleared by one month and $60 \%$ cleared in two months. ${ }^{4}$ Mandle et al in their study found that with amoxicillin, the clearance of effusion was significantly greater in the control groups. ${ }^{5}$ Blue stone et al in their study found that the clearance of effusion did not differ between the groups who received a decongestants antihistamine and placebo. ${ }^{6}$

Basing the rationale for adenoidectoimy in children with Otitis media on size alone has little scientific basis. But paradise et al, have demonstrated the effectiveness of adenoidectoimy in the management of secretary otitis media. ${ }^{7}$ Further clinical evidence from the above studies indicates that the effect of adenoidectomy is independent of adenoid size. ${ }^{8}$ The other classic rationale is improvement in Eustachian tube function. Honjo showed improvement in equilibration of positive middle ear pressure after adenoidectomy but no change in the ability to equilibrate negative pressure and no change in the static opening pressure of the tube. ${ }^{9}$ Obstruction of the Eustachian tube either anatomic or functional is a logical rationale for the procedure.
The goal of using tympanostomy tubes is to provide adequate ventilation to the tympanum. Removal of the middle ear effusion and restoration of an aerated tympanum results in prompt return of hearing to the pre infection levels in the vast majority of patients. Experimental evidence suggests that mucosal hyperplasia of the tympanum will revert to a more normal condition with aeration. ${ }^{10}$ Gates et al found a significantly better outcome in terms of hearing, decreased duration of middle ear effusion, longer time to recurrence, and fewer repeat operations in the children with tympanostomy tubes as compared with those undergoing myringotomy and aspiration. ${ }^{11}$ Similar conclusions were reached by Madel, Bluestone, and Paradise. ${ }^{12}$ Paradise argued that tympanostomy tubes should be used as the initial procedure of choice for patients with persistent OME, because tympanostomy tube placement is less harmful and less expensive than adenoidectomy. ${ }^{12}$ They reserve adenoidectomy for cases with recurrent secretary otitis media.

\section{CONCLUSION}

From our study it is evident that secretory otitis media is a treatable cause of conductive hearing loss in children. In children, Eustachian tube dysfunction was secondary to functional or mechanical obstruction and is the most common precipitating factor for secretory otitis media. Gastro-esophageal reflux disease was found to be associated with almost all adult patients. It has to be studied whether control of acid reflux can have any effect in these patients. From our study it was evident that medical management helps in the control of acute episodes of secretory otitis media which is associated with frequent relapse and recurrence. Surgical management in the form of adenoidectomy/myringotomy with grommet insertion has better long term outcome in terms of hearing impairment and disease relapse and recurrence. A long term follow up is needed to assess the disease relapse and recurrence. Long term follow up is also needed to study the various sequlae of secretory otitis media like adhesive otitis media and cholesteatoma.

Funding: No funding sources

Conflict of interest: None declared

Ethical approval: The study was approved by the Institutional Ethics Committee

\section{REFERENCES}

1. Bluestone CD. State of the art: definitions and classifications. In: Liu DJ, Bluestone CD, Klien JO, Nelson JD, Eds. Recent advances in otitis media with effusion. Proceedings of the 3rd International Conferences. Ontario: Decker and Mosby;1984.

2. Zielhuis GA, Rach GH, V an den Basch A, V an den Broek P. The prevalence of otitis media with effusion: a critical review of the Literature. Clin Otolaryngol. 1990;15:283-8. 
3. Tos M, Holm-Jensen S, Sorensen CH, Mogensen C. Spontaneous course and frequency of secretory otitis in 4-year-old children. Arch Otolaryngol. 1982;108:4-10.

4. Gates GA, Wachtendorf C, Richard H, Erwin M. Medical treatment of chronic otitis media with effusion (secretory Otitis media). Otolaryngol Head Neck Surg. 1986;94:350-4.

5. Mandel EM, Rockette HE, Bluestone CD, Paradise JL, Nozza RJ. Efficacy of amoxicillin with and without decongestant- antihistamine for otitis media with effusion in children. $\mathrm{N}$ Engl $\mathrm{J}$ Med. 1987;316:432-7.

6. Bluestone CD, Cantekin EI, Beery QC. Certain effects of adenoidectomy on eustachian tube ventilatory function. Laryngoscope. 1975;85:11327.

7. Paradise JL, Bluestone CD, Rogers KD, Taylor FH, Colborn DK, Bachman RZ, et al. Efficacy of Adenoidectomy for Recurrent Otitis Media in Children Previously Treated With TympanostomyTube Placement: Results of Parallel Randomized and Nonrandomized Trials. JAMA. 1990;263(15):2066-73.

8. Fujioka M, Young LW, Girdany BR. Radiographic evaluation of adenoidal size in children: adenoidalnasopharyngeal. Am J Radiol. 1979;133:401-404.
9. Honjo I, Ushiro K, Mitoma T. Endoscopic observation of the eustachian tube in otitis media with effusion. In: Lim DJ, ed. Recent advances in otitis media with effusion. Decker, Philadelphia; 1984: 238-240.

10. Pichichero ME, Berghash LR, Hengerer AS. Anatomic and audiologic sequelae after tympanostomy tube insertion or prolonged antibiotic therapy for otitis media. Pediatr Infect Dis J. 1989;8:780-7.

11. Gates GA, Avery CA, Prihoda TJ, Cooper JC. Effectiveness of adenoidectomy and tympanostomy tubes in the treatment of chronic otitis media with effusion. N Engl J Med. 1987;31:1444-51.

12. Mandel EM, Bluestone CD, Paradise JL. Myringotomy with and without tympanostomy tube insertion in the treatment of chronic otitis media with effusion. Arch Otolaryngol Head Neck Surg. 1989;115:1217-24.

Cite this article as: Rajprakash DY, Venkatesan SKR, Alisulthan AR, Aravindhan V, Mothilal KB. Management of secretory otitis media: a prospective randomised study comparing medical management with early surgical intervention. Int J Otorhinolaryngol Head Neck Surg 2019;5:883-7. 